\title{
Gender-dependent associations between socioeconomic status and metabolic syndrome: a cross-sectional study in the adult Saudi population
}

\author{
Nasser M Al-Daghri 1,2,3*, Khalid M Alkharfy ${ }^{1,2,4}$, Omar S Al-Attas ${ }^{1,2,3}$, Nasiruddin Khan², Hanan A Alfawaz ${ }^{3,5}$, \\ Saad A Alghanim ${ }^{6}$, Mansour A Al-Yousef ${ }^{7}$, Abdulrahman S M Al-Ajlan ${ }^{8}$ and Majed S Alokail ${ }^{1,2,3}$
}

\begin{abstract}
Background: To determine the gender-dependent association of socio-economic status variables with the prevalence of metabolic syndrome (MetS) in the adult Saudi population.

Methods: A total of 9164 adult Saudis (aged 18-70 years) were included in this cross-sectional study. Marital status, income, education, and occupation were used as socio-economic indicators while behavioral factor like physical exercise was also taken into account. MetS was defined using the criteria based from the National Cholesterol Education Program Adult Treatment Panel III (NCEP-ATP III).

Results: In males, the odds ratio (OR) of harboring MetS was higher in married [OR1.6 (Confidence Interval (Cl) $1.1,2.4) ; \mathrm{p}<0.03]$, and high income class [OR 2.3(Cl 1.5, 3.5); $\mathrm{p}<0.001]$ and lowest in retired and unemployed individuals $[1.4(1.0,1.9) ; p<0.04,0.61(0.45,0.82) ; p<0.001]$ respectively. In females, MetS was inversely related to high income [OR $0.70(\mathrm{Cl} 0.46,1.1) ; \mathrm{p}<0.09$ ] and education level [OR $0.38(\mathrm{Cl} 0.26,0.56) ; \mathrm{p}<0.001]$, and was significantly higher in the unemployed class [OR 1.6 (Cl 1.2, 2.2); $p<0.004]$.
\end{abstract}

Conclusions: The prevalence of MetS is significantly high among retired, married and high-earning Saudi males while in females, high earners and high education seem to confer a protective effect against MetS.

Keywords: Gender, Socioeconomic status, Marital status, Income, Education, Saudi Arabia

\section{Background}

Metabolic syndrome (MetS), considered to be a global epidemic [1], encompasses several risk factors including obesity, elevated arterial blood pressure, impaired glucose metabolism, and dyslipidemia. If it remains unchecked, it could lead towards higher susceptibility to type 2 diabetes, some cancers and cardiovascular disease [2-5]. The most widely used criteria for defining MetS is the NCEP ATP III definition [6] as it does not have a prerequisite risk factor as opposed to other definitions, favoring large scale screening for MetS assessment. MetS

\footnotetext{
* Correspondence: aldaghri2011@gmail.com

'Center of Excellence in Biotechnology Research, King Saud University, Riyadh 11451, Kingdom of Saudi Arabia

2Biomarkers Research Program, Biochemistry Department, College of Science, King Saud University, PO Box, 2455, Riyadh 11451, Kingdom of Saudi Arabia
} Full list of author information is available at the end of the article is influenced by various factors including diet, physical activity, gender, genetic background and age [7]. Moreover, the prevalence varies depending on the definition, as well as the composition of the population studied [8]. Worldwide, prevalence estimates for MetS in adult population varies from $8 \%$ in India [9] to $24.2 \%$ in United States [10] in men and from $7 \%$ in France [11] to $46.5 \%$ in India [12] in women. In Europe [13,14] and other Asian countries [15], the prevalence of MetS is higher in men than in women.

Based on the results of several studies and taking into consideration the different definitions, the prevalence of MetS in Gulf Cooperative Council (GCC) (Bahrain, Kuwait, Oman, Qatar, Saudi Arabia and the United Arab Emirates) countries varies from 20.7-37.2\% [ATPIII definition [6] and 29.6-36.2\% [International Diabetes Federation 
(IDF) definition [16] for males, and 32.1-42.7\% (ATPIII definition) and 36.1-45.9\% (IDF definition) for females $[17,18]$. However, in case of females, the prevalence rates of MetS in GCC states are almost 10-15\% higher than in most developed countries $[10,19]$.

The strong correlation between age and the prevalence of MetS has been established, as several studies have consistently demonstrated the high prevalence of MetS with advancing age $[10,11]$. A number of studies strongly link the socio-economic status with prevalence of MetS in different populations [20,21]. Although, the exact mechanism involved in this relationship is not clear, the socio-economic status may influence MetS and its components by affecting environmental and social factors $[22,23]$. Therefore, as an initial preventive approach to understand and manage the occurrence of MetS, it appears warranted to study the social and economic variables that could lead towards its high prevalence [24,25].

The rapid economic growth of Saudi Arabia has affected the behavior of the population in ways that is favorable for the manifestation of MetS [26]. In different age groups from different parts of Saudi Arabia, overweight and obesity are related with demographic, genetic and life style factors [27-30]. To date, there is limited information from Saudi Arabia in relation to cardiovascular diseases with demographic variables [31] and its possible link to MetS in males and females [32,33], respectively. To the best of our knowledge, no study specifically intended to relate the full MetS with socio-economic status variables based on gender difference with such a broad range of age groups.

The present study aims to assess the prevalence of full MetS based on NCEP ATP III diagnostic criteria and to examine its associations with socio-economic status variables (marital status, income, education and profession) within a broad age range (18-70 years) in adult Saudi males and females.

\section{Methods}

Participants and recruitment

A total of 9164 consenting Saudi adults [aged 18-70 years; 4417 males (mean age $41.35 \pm 14.7$ ) and 4747 females $(37.4 \pm 13.5)]$ were included in this cross-sectional study. The participants were part of the Biomarkers Screening Program Database, a collaboration between the Biomarkers Research Program (BRP) of King Saud University and the Ministry of Health in Riyadh, Kingdom of Saudi Arabia (RIYADH Cohort) done in March 1August 31, 2009. Patient information was obtained from the database of more than 17,000 individuals. The information of individuals included in this study were based on inclusion criteria irrespective of disease status (diabetic, hypertensive and dyslipidemic patients were not excluded to avoid selection bias). Pregnant females were excluded from the study. Patients were recruited randomly from their homes using the cluster sampling strategy. They visited their nearest primary healthcare center (PHCC) that span the entire Riyadh region. The population of each PHCC was taken as a cluster, and the allocations of the required numbers of patients were proportional to the populations served by the PHCCs. No expatriates were included in the conduct of this study. Ethical approval was obtained from the Ethics Committee of the College of Science Research Center of King Saud University, Riyadh, Saudi Arabia [34].

\section{Anthropometric data and biochemical analyses}

Subjects were requested to visit their respective PHCCs after overnight fasting ( $>10$ hours) for anthropometry and blood withdrawal by the PHCC nurse and physician on duty, respectively. Anthropometry included height (rounded off to the nearest $0.5 \mathrm{~cm}$ ), weight (rounded off to the nearest $0.1 \mathrm{~kg}$ ), waist and hip circumference (centimeters), and mean systolic and diastolic arterial blood pressure $(\mathrm{mmHg})$ (average of two readings after resting for 3-5 minutes). The body mass index (BMI) was calculated as weight in kilograms divided by height in squared meters. A fasting blood sample was collected and transferred immediately to a non-heparinized tube for centrifugation. Collected serum was then transferred into a pre-labeled plain tube, stored in ice and delivered to the Biomarkers Research Program (BRP) laboratory of King Saud University, Riyadh, Saudi Arabia, on the same day of collection for immediate storage at $-20^{\circ} \mathrm{C}$ freezer pending further analysis. The blood samples were analyzed for fasting glucose and lipid profile including HDL-C, LDL-C, and triglycerides using a chemical analyzer (Konelab, Espoo, Finland).

Participants completed an interviewer-administered questionnaire covering information on socioeconomic status, physical exercise, personal medical history, family history, and current drug therapy. Socio-economic status was assessed based on the questionnaire that included marital status, monthly income, occupation, and education. Marital status was recorded in four categories: single, married, divorced, and widowed. Total monthly household income was divided in categories [depending on the amount of Saudi Arabian Riyal (1SAR = 0.266USD): upper income class $(10,000-20,000)$, middle income class per month $(>5000-10,000)$; and low income class $(<5000)$. The classification of occupation was based on current employment status and sectors, as government, private, retired and unemployed (non-officially employed). Education level was categorized as: uneducated $(<6$ years), precollege (7-12 years), and college/high education ( $>12$ years). Physical activity was divided into five groups according to frequency of exercise: daily, three or four times per week, one or two three times per week, few times a month, and once a month. 


\section{Statistical analyses}

Statistical analysis was performed using SPSS version 16.0 (SPSS, Chicago, IL, USA). Demographic and biochemical characteristics of the study population, were compared using the Chi-square or Fisher's exact test for categorical variables. Evaluation of trend between age groups was analyzed using the Cochran-Armitage trend test. Odds ratios (ORs) and 95\% confidence intervals (95\% CIs) for metabolic syndrome with various socio-economic parameters were calculated using multivariate logistic regression analysis adjusted for age. $\mathrm{P}$ values less than 0.05 were accepted to indicate statistically significant differences.

\section{Metabolic syndrome definition}

All subjects were screened for MetS. Definition of MetS and its components were based on the ATPIII Guidelines [6], by the presence of three or more of the following risk factors: central obesity (Waist circumference $\geq 90 \mathrm{~cm}$ for men and $\geq 80 \mathrm{~cm}$ for women); systolic blood pressure $\geq 130 \mathrm{mmHg}$ and/or diastolic blood pressure $\geq 85 \mathrm{mmHg}$; fasting glucose $\geq 100 \mathrm{mg} / \mathrm{dL}$; TG $\geq 150 \mathrm{mg} / \mathrm{dL}$; HDL-C levels (<40 mg/dL for men and $<50 \mathrm{mg} / \mathrm{dL}$ for women). In addition, subjects who were on medications taking antihypertensive or antidiabetic drugs were considered to have elevated BP or high fasting glucose levels, respectively.

\section{Results}

The overall prevalence of MetS and its individual components based on demographic and socioeconomic status variables are presented in Table 1, following ATPIII criteria [6].

As regards the marital status, the widow class presented higher prevalence of metabolic syndrome (74.2\%) as compared to other classes (single, married and divorced). A significant inverse relationship of income with prevalence of MetS was found, being highest in the upper class $(48.9 \%)$ than other classes. Level of education had an

Table 1 Overall prevalence of MetS according to demographic and socio-economic status characteristics based on ATPIII Criteria

\begin{tabular}{|c|c|c|c|c|c|c|}
\hline & $\begin{array}{l}\text { Waist Circumference } \\
\text { (Men > 102, Women } \\
>88 \mathrm{~cm}), \mathrm{n}(\%)\end{array}$ & $\begin{array}{c}\text { Triglycerides } \\
>1.7 \mathrm{mmol} / \mathrm{l}, \\
\mathrm{n}(\%)\end{array}$ & $\begin{array}{c}\text { FBG } \\
(\geq 6.1 \mathrm{mmol} / \mathrm{l}), \\
\mathrm{n}(\%)\end{array}$ & $\begin{array}{c}\text { Hypertension } \\
(\geq 130 / 85 \mathrm{mmHg}), \\
\mathrm{n}(\%)\end{array}$ & $\begin{array}{c}\mathrm{HDL}(\text { Men }<1.03 \mathrm{mmol} / \mathrm{l}) ; \\
\text { (Women }<1.29 \mathrm{mmol} / \mathrm{l}) \\
\mathrm{n}(\%)\end{array}$ & $\begin{array}{l}\text { MetS } \\
\text { (ATPIII), } \\
\text { n (\%) }\end{array}$ \\
\hline Male & $1480(33.5)^{*}$ & $2200(49.8)^{*}$ & $1829(41.4)^{*}$ & $1572(35.6)^{*}$ & $3781(85.6)^{*}$ & $2085(47.2)^{*}$ \\
\hline Female & $2606(54.9)$ & $1281(27.0)$ & $1571(33.1)$ & $1234(26.0)$ & $3798(80.0)$ & $1913(40.3)$ \\
\hline \multicolumn{7}{|l|}{ Marital status } \\
\hline Single & $409(18.0)$ & 439 (19.3) & $330(14.5)$ & $222(9.7)$ & $1695(74.6)$ & $296(13.0)$ \\
\hline Married & $3322(51.9)$ & $2823(44.1)$ & $2800(43.7)$ & $2338(36.5)$ & $5481(85.5)$ & $3374(52.7)$ \\
\hline Divorced & $101(73.5)$ & $56(40.8)$ & $47(34.7)$ & $42(30.6)$ & $120(87.8)$ & $70(51.0)$ \\
\hline Widowed & $254(73.4)^{*}$ & $163(46.9)^{*}$ & $223(64.1)^{*}$ & $204(58.6)^{*}$ & $283(81.2)^{*}$ & $258(74.2)^{*}$ \\
\hline \multicolumn{7}{|l|}{ Income } \\
\hline Low income & $2075(48.7)$ & $1180(27.7)$ & $1334(31.3)$ & $1090(25.6)$ & $3409(80.0)$ & $1612(37.8)$ \\
\hline Middle Class & $1182(40.7)$ & 1354 (46.6) & $1231(42.4)$ & $953(32.8)$ & $2491(85.7)$ & $1409(48.5)$ \\
\hline Upper Class & $829(41.5)^{*}$ & $947(47.4)^{*}$ & $835(41.8)^{*}$ & $763(38.2)^{*}$ & $1679(84.0)^{*}$ & $977(48.9)^{*}$ \\
\hline \multicolumn{7}{|l|}{ Education } \\
\hline Uneducated (< 6 yrs) & $1697(66.8)$ & $1071(42.2)$ & $1324(52.3)$ & $1172(46.2)$ & 2121 (83.6) & $1594(62.8)$ \\
\hline Pre-college (7-12 yrs) & $1701(39.4)$ & $1740(40.3)$ & $1553(36.1)$ & $1207(28.0)$ & $3629(84.2)$ & $1798(41.8)$ \\
\hline Higher Educated (>12 yrs) & $688(29.7)^{*}$ & $670(28.9)^{*}$ & $523(22.6)^{*}$ & $427(18.4)^{*}$ & $1829(78.9)^{*}$ & $606(26.1)^{*}$ \\
\hline \multicolumn{7}{|l|}{ Profession } \\
\hline Government & $1172(40.0)$ & $1350(46.0)$ & $1075(36.8)$ & $850(29.0)$ & 2451 (83.6) & $1260(43.0)$ \\
\hline Private & $150(34.1)$ & $215(48.8)$ & $188(42.7)$ & $147(33.5)$ & $405(92.1)$ & $228(51.8)$ \\
\hline Retired & $382(44.4)$ & $490(56.9)$ & $546(63.4)$ & $457(53.1)$ & $764(88.8)$ & $592(68.6)$ \\
\hline Unemployed & $2382(48.3)^{*}$ & $1426(28.9)^{*}$ & $1591(32.3)^{*}$ & $1352(27.4) *$ & $3959(80.3)^{*}$ & $1918(38.8)^{*}$ \\
\hline \multicolumn{7}{|l|}{ Exercise } \\
\hline Daily or 3-4 times/week & $2813(43.8)$ & $2215(34.5)$ & 2279 (35.5) & $1716(26.7)$ & $5160(80.2)$ & $2733(42.5)$ \\
\hline 1-2 times/week & $794(46.7)$ & $800(47.0)$ & $684(40.2)$ & $598(35.2)$ & 1495 (87.9) & $764(44.9)$ \\
\hline Few times/Once a month & $479(46.3)^{*}$ & $466(45.1)^{*}$ & $437(42.2)^{*}$ & $492(47.6)^{*}$ & $924(88.6)^{*}$ & $501(48.3)^{*}$ \\
\hline
\end{tabular}

${ }^{*} \mathrm{p}<0.05$ : comparison between various classes of demographic and socioeconomic status characteristics. 
inverse relation, with the lowest prevalence of MetS in higher education level (26.1\%) than uneducated and precollege subjects. Based on occupation, the officially unemployed participants presented the lowest (38.8\%) prevalence of MetS than other professional classes. Physical exercise showed an inverse association with the prevalence of MetS, being highest in the category with 'few times a month/once a month' group (48.3\%) than other groups.

The pattern of distribution regarding prevalence of MetS (\%) based on age groups and sex is presented in Figure 1. The overall prevalence of MetS increased uniformly with increase in age in both males and females. With age, the prevalence of MetS increased from 9.1 among females of age group $<20$ yrs to 70.8 in $>65 \mathrm{yrs}$, representing a significant trend $(\mathrm{p}<0.001)$. Similar results were observed in males with a significant increase from 7.6 to 66.7 ( $p<0.001)$. Table 2 shows a significant gender difference among various socioeconomic variables and behavioral factor. The prevalence of MetS was $47.2 \%$ for males and $40.3 \%$ for females.

Table 3 presents the odds ratios [ORs (95\% CI)] indicating the prevalence of having the full MetS with different socio-economic status variables in males. After adjustment for age, a significant relation showing high prevalence of MetS within the married class was observed [1.6 (1.1, 2.4); $\mathrm{p}<0.03]$. The income group revealed a higher prevalence in the middle as well as upper income classes $[2.2(1.5,3.5) ; \mathrm{p}<0.001$ and $[2.3(1.5,3.5)$; $\mathrm{p}<0.001$ ], respectively, than low income subjects. The retired and officially unemployed males showed the highest and lowest odds for MetS [1.4(1.0, 1.9); $\mathrm{p}<0.04,0.61$ $(0.45,0.82) ; \mathrm{p}<0.001]$ respectively. Self-assessed physical exercise was not significantly influencing MetS in male participants.

The odds ratios for the prevalence of having the full MetS in females is presented in Table 4. The prevalence of MetS was significantly higher among unemployed women [1.6 (1.2, 2.2); $\mathrm{p}<0.004]$ and significantly lower in middle, upper income class and higher education level [0.65 (0.48, 0.89); $\mathrm{p}<0.008,0.70(0.46,1.1 ; \mathrm{p}<0.09)]$ and [0.38 (0.26, 0.56); $\mathrm{p}<0.001]$ respectively.

\section{Discussion}

The results of this study, one of the largest populationbased studies regarding MetS in Saudi Arabia, demonstrate the high prevalence of MetS in both adult males than females. The results showed a significant positive relationship between married status and high income class in males and a higher prevalence of MetS. Moreover, officially unemployed males showed the lowest prevalence of having the full MetS. In females, those with no professional activities were more predisposed to develop MetS while the higher education and high

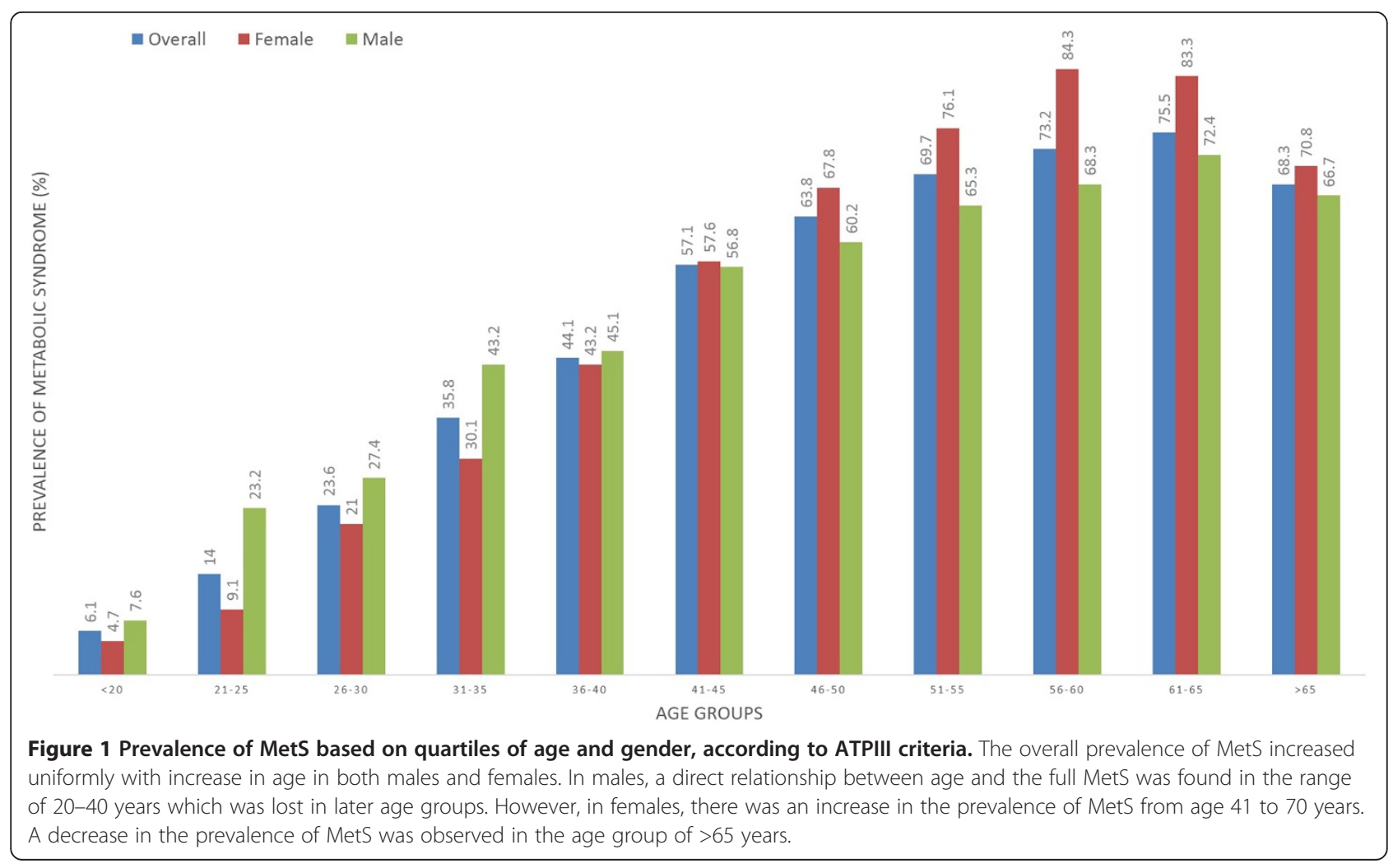


Table 2 Gender difference among socioeconomic variables and behavioral factor

\begin{tabular}{|c|c|c|c|}
\hline & Males & Females & $p$ value \\
\hline $\mathbf{N}$ & 4417 & 4747 & \\
\hline Marital Status (\%) & & & 0.008 \\
\hline Single & 22.5 & 26.9 & \\
\hline Married & 77.2 & 63.2 & \\
\hline Divorced & 0.1 & 2.7 & \\
\hline Widowed & 0.2 & 7.2 & \\
\hline \multicolumn{4}{|l|}{ Income (\%) } \\
\hline Low income & 16.1 & 74.9 & $<0.001$ \\
\hline Middle Class & 48.2 & 16.3 & \\
\hline Upper Class & 35.7 & 8.8 & \\
\hline \multicolumn{4}{|l|}{ Education (\%) } \\
\hline Uneducated (<6 yrs) & 16.9 & 38.0 & 0.003 \\
\hline Pre college (7-12 yrs) & 56.0 & 38.3 & \\
\hline Higher Education (>12 yrs) & 27.1 & 23.7 & \\
\hline \multicolumn{4}{|l|}{ Profession (\%) } \\
\hline Government & 50.7 & 14.5 & $<0.001$ \\
\hline Private & 8.8 & 1.2 & \\
\hline Retired & 18.7 & 0.7 & \\
\hline Unemployed & 21.8 & 83.6 & \\
\hline \multicolumn{4}{|l|}{ Exercise (\%) } \\
\hline Daily or 3-4 times/week & 57.7 & 80.8 & 0.002 \\
\hline 1-2 times/week & 26.2 & 12.2 & \\
\hline Few times/Once a month & 16.1 & 7.0 & \\
\hline Mets (\%) & 47.2 & 40.3 & $<0.001$ \\
\hline
\end{tabular}

p-value significant at $<0.05$.

income level seem to confer a protective effect against MetS.

The present results, with an increased prevalence of MetS with advancing age in both genders, support several other studies performed in different populations $[7,35,36]$. The over-all prevalence of MetS in males was higher only in the age group of 40 years and below as compared to females, probably due to the presence of high number of younger subjects in this age group. However, the females in the age group of 45-60 years emerged as the highest contributor in the prevalence of MetS as compared to males. The present results supports the study performed by Al-Daghri and colleagues in urban Saudi adults, demonstrating higher prevalence of MetS in males only in the younger age groups (40 years and below) which is eventually replaced by females in the older age groups (49-55 years) [37]. In the present study, a decrease in the prevalence of MetS in the age group $>65$ years was noted in both males and females. The most probable reason for this low prevalence is the lower number of individuals belonging to this age group.

The full MetS is associated significantly with marital status in adults (20-65 yrs) as shown by Sirdah et al. [38]. Studies in females from Iran [39] and Morocco [40] demonstrated a similar trend. The present study partially supports the above studies showing higher prevalence of MetS in married couples but only in males as compared to other classes.

Gender-related differences in MetS are a matter of controversy with no relation to income or education level in males and females [41], a positive association of MetS with higher education and income among males but not in females [42], or an inverse association of income with MetS only in females and educational level associated with MetS in both genders [20]. The higher socioeconomic groups in Tunisian adults demonstrated higher MetS rates [43]. In addition, Park and colleagues observed the higher prevalence of MetS in males with highest household income [44]. Ferguson et al. [42] demonstrated the association of high income with increased odds of having the MetS among males, adjusted for age-group. However, these findings contradicts the results for developed countries, where lower income is associated with higher prevalence of MetS $[45,46]$. Depending on the developmental level of specific countries [47], it has been shown that in developed countries, CVD risk factor burden are inversely related to socioeconomic status while a positive association exists in less developed or low and middle income countries [47,48]. The present results are in agreement with the findings of Ferguson and Park et al. [42,44] showing a positive association between higher income and the prevalence of metabolic syndrome in males but showed no relation of education with such prevalence. The rapidly expanding economic status of Saudi Arabia has affected its cultural lifestyle during the last few decades, pushing towards physical inactivity and sedentary behavior, a leading cause for increasing rate of obesity [49] that could also be an important contributing factor towards higher prevalence of MetS. The fast economic growth in Saudi Arabia diverted the general population towards more dependency on automobile, telecommunication technology, use of high fat and dense-caloric foods, and decreased occupationalwork demands. These factors could contribute to minimize requirement for physical activity and add more sedentary lifestyles [50]. In addition, the habit of eating out has been highly prevalent in most middle-east countries including Saudi Arabia, because of an increase in income per capita among these people [51].

Based on religion and cultural aspects, the males in Saudi Arabia had much more accessibility and opportunity to eat out more frequently than females and therefore pay less attention towards healthy food choices. It has also 
Table 3 Prevalence of metabolic syndrome according to socio-economic variables, in males

\begin{tabular}{|c|c|c|c|c|}
\hline Marital status & $\begin{array}{l}\text { Odds ratio }^{a} \\
(95 \% \mathrm{Cl})\end{array}$ & $P$ value & $\begin{array}{l}\text { Odds ratio } \\
(95 \% \mathrm{Cl})\end{array}$ & $\mathrm{p}$ value \\
\hline Single & 1.0 & & 1.0 & \\
\hline Married & $6.3(4.6,8.5)$ & $<0.001$ & $1.6(1.1,2.4)$ & 0.03 \\
\hline Divorced & $4.9(0.30,80.2)$ & 0.26 & $0.96(0.05,16.8)$ & 0.98 \\
\hline Widowed & $9.9(0.88,110.9)$ & 0.06 & $1.9(0.15,22.6)$ & 0.61 \\
\hline \multicolumn{5}{|l|}{ Income } \\
\hline Low Income & 1.0 & & 1.0 & \\
\hline Middle Class & $6.1(4.2,8.7)$ & $<0.001$ & $2.2(1.5,3.5)$ & $<0.001$ \\
\hline Upper Class & $6.3(4.3,9.1)$ & $<0.001$ & $2.3(1.5,3.5)$ & $<0.001$ \\
\hline \multicolumn{5}{|l|}{ Profession } \\
\hline Government & 1.0 & & 1.0 & \\
\hline Private & $1.5(1.1,2.1)$ & 0.02 & $1.4(0.97,2.1)$ & 0.06 \\
\hline Retired & $2.6(2.0,3.5)$ & $<0.001$ & $1.4(1.0,1.9)$ & 0.04 \\
\hline Unemployed & $0.39(0.30,0.52)$ & $<0.001$ & $0.61(0.45,0.82)$ & 0.001 \\
\hline \multicolumn{5}{|l|}{ Education } \\
\hline Uneducated (<6 yrs) & 1.0 & & 1.0 & \\
\hline Precollege (7-12 yrs) & $0.61(0.46,0.81)$ & 0.001 & $1.2(0.94,1.8)$ & 0.10 \\
\hline Higher Education (>12 yrs) & $0.40(0.29,0.54)$ & $<0.001$ & $1.0(0.70,1.4)$ & 0.95 \\
\hline \multicolumn{5}{|l|}{ Exercise } \\
\hline Daily or 3-4 times/week & 1.0 & & 1.0 & \\
\hline 1-2 times/week & $1.2(0.92,1.6)$ & 0.15 & $1.3(0.97,1.8)$ & 0.06 \\
\hline Few times/Once a month & $1.2(0.88,1.7)$ & 0.22 & $1.3(0.92,1.9)$ & 0.12 \\
\hline
\end{tabular}

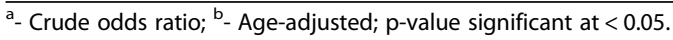

been shown that the purchasing power of males with increase in earnings is not balanced for the adaptation of a healthier lifestyle [52,53]. Therefore, in present study, a positive association between prevalence of MetS and higher income class in males could be due to sedentary lifestyle, lack of proper food choices and the increased ability to purchase foods as compared to females belonging to the same income status.

Furthermore, males in the lower income class seem to be involved with more physically demanding occupations and hence present a lower prevalence of metabolic syndrome than females. In the present study, the retired and officially unemployed males presented the highest and lowest prevalence of MetS respectively. As explained earlier, the unemployed group may mostly consist of males involved in more physically demanding activities which may prove beneficial against developing MetS, as compared to working in administrative or academic fields.

As compared to males, there was no significant association between age-adjusted marital status and prevalence of MetS in females. In a recent study, the education level was demonstrated as an important socioeconomic determinant of MetS only in females [54]. There are studies demonstrating a less prominent inverse association between educational level and MetS in males as compared to females $[24,55]$. Zhan and colleague's demonstrated high risk of MetS among females with lower education and household monthly income level, while such association was not significant in males [56]. Similar results were observed in an urban population in Kenya showing an inverse association of the presence of MetS with attainment of higher education in females but not in males [57]. Moreover, the inverse association of income and education with prevalence of MetS in females has been documented in several studies $[20,39,58,59]$. The present results support the above findings showing a strong, significant inverse relation between high income and education with prevalence of MetS. The reason for this association in females may be related to the positive and favorable effect of education in preferring adequate food sources $[22,60]$ and adopting healthy behaviors $[61,62]$ that could in turn lead to lower prevalence of MetS. Moreover, females are more health conscious than males and use their knowledge to acquire healthier lifestyle patterns. In the present study, the OR for MetS increased in the unemployed female category. Since, these are mostly housewives with almost negligible involvements in any type 
Table 4 Prevalence of metabolic syndrome according to socio-economic variables in females

\begin{tabular}{|c|c|c|c|c|}
\hline Marital status & $\begin{array}{l}\text { Odds ratio }^{a} \\
(95 \% \mathrm{Cl})\end{array}$ & $P$ value & $\begin{array}{l}\text { Odds ratio }^{\text {b }} \\
(95 \% \mathrm{Cl})\end{array}$ & $\mathrm{p}$ value \\
\hline Single & 1.0 & & 1.0 & \\
\hline Married & $8.4(6.1,11.6)$ & $<0.001$ & $1.3(0.85,2.1)$ & 0.21 \\
\hline Divorced & $9.1(4.7,17.4)$ & $<0.001$ & $1.2(0.58,2.6)$ & 0.56 \\
\hline Widowed & $25.4(15.4,41.9)$ & $<0.001$ & $1.5(0.77,2.8)$ & 0.23 \\
\hline \multicolumn{5}{|l|}{ Income } \\
\hline Low income & 1.0 & & 1.0 & \\
\hline Middle class & $0.81(0.62,1.1)$ & 0.12 & $0.65(0.48,0.89)$ & 0.008 \\
\hline Upper class & $0.64(0.45,0.92)$ & 0.01 & $0.70(0.46,1.1)$ & 0.09 \\
\hline \multicolumn{5}{|l|}{ Profession } \\
\hline Government & 1.0 & & 1.0 & \\
\hline Private & $0.50(0.16,1.5)$ & 0.22 & $1.0(0.28,3.6)$ & 0.98 \\
\hline Retired & $1.8(0.59,5.6)$ & 0.29 & $0.77(0.22,2.6)$ & 0.68 \\
\hline Unemployed & $1.5(1.2,2.1)$ & 0.003 & $1.6(1.2,2.2)$ & 0.004 \\
\hline \multicolumn{5}{|l|}{ Education } \\
\hline Uneducated (<6 yrs) & 1.0 & & 1.0 & \\
\hline Precollege (7-12 yrs) & $0.28(0.23,0.36)$ & $<0.001$ & $0.82(0.62,1.1)$ & 0.17 \\
\hline Higher education ( $>12 \mathrm{yrs}$ ) & $0.09(0.07,0.13)$ & $<0.001$ & $0.38(0.26,0.56)$ & $<0.001$ \\
\hline \multicolumn{5}{|l|}{ Exercise } \\
\hline Daily or 3-4 times/week & 1.0 & & 1.0 & \\
\hline 1-2 times/week & $1.3(0.94,1.8)$ & 0.10 & $1.3(0.91,1.9)$ & 0.13 \\
\hline Few times/Once a month & $0.71(0.45,1.1)$ & 0.15 & $0.67(0.39,1.1)$ & 0.13 \\
\hline
\end{tabular}

${ }^{a}$-Crude odds ratio; ${ }^{b}$ - Age adjusted. $p$-value significant at $<0.05$.

of physical exercise, such sedentary behaviors are a plausible cause for the high prevalence of metabolic syndrome [63]. In Saudi Arabia, females have fewer chances to move outside their homes and have limited opportunities to attend health centers [64]. Saudi Arabian culture does not allow females to undertake outdoor physical activities, and related facilities for females are lacking. In addition, the hot climate, use of automobiles even for shorter distances, and hiring of domestic helpers, seems to contribute to physical inactivity in daily life [65].

As in males, no significant association was observed between physical exercise and prevalence of metabolic syndrome in females. There are some limitations while interpreting the results of this study. Firstly, the socioeconomic status variables like household income and education are interrelated and thus it is not easy to demonstrate the individual participation and association of these variables with MetS and its prevalence. Being a cross sectional study, the results are unable to show a causal relationship between MetS and the socio-economic status.

\section{Conclusion}

Gender influenced the socio-economic status indicators and its association with the prevalence of MetS. The prevalence was more frequent in males belonging to married, high income and retired individuals. On the contrary, higher education and income played an important role in decreasing the prevalence of syndrome in females, with no such education gradient in males. Apart from health awareness education programs for proper life style behavior particularly in males, it is recommended that the jobless and retired individuals (males and females) should indulge in some sort of physical activity and be educated for proper food choices, as preliminary precautions in order to decrease the high prevalence of metabolic syndrome. Preventive strategies and knowledge regarding modifiable risk factors must be taken into account in both adult males and females.

\section{Abbreviations}

NCEP ATP III: National Cholesterol Education Program Adult Treatment Panel III; IDF: International Diabetes Federation; GCC: Gulf Cooperative Council; PHCC: Primary healthcare center; HDL-C: High density lipoprotein-cholesterol; LDL-C: Low density lipoprotein-cholesterol; TG: Triglycerides; FBG: Fasting blood glucose; SAR: Saudi Arabian Riyal; USD: United States Dollar.

Competing interests

The authors declare that they have no competing interests. 


\section{Authors' contributions}

NMA, KMA, and OSA contributed in the design, subject recruitments and data collection. NK, HAA, ASMA and SAA carried out sample analysis, interpretation, and preparation of draft manuscript. ASMA, MAA, and MSA edited the final version of the manuscript. All authors read and approved the final manuscript.

\section{Acknowledgements}

The authors are grateful to the College of Science Research Center, King Saud University for funding the present study. Special thanks go to Mr. Benjamin Vinodson for the statistical analysis of data. We also thank the Prince Mutaib Chair for Biomarkers of Osteoporosis for technical support.

\section{Author details}

${ }^{1}$ Center of Excellence in Biotechnology Research, King Saud University, Riyadh 11451, Kingdom of Saudi Arabia. ${ }^{2}$ Biomarkers Research Program, Biochemistry Department, College of Science, King Saud University, PO Box, 2455, Riyadh 11451, Kingdom of Saudi Arabia. ${ }^{3}$ Prince Mutaib Chair for Biomarkers of Osteoporosis, Biochemistry Department, College of Science, King Saud University, Riyadh 11451, Kingdom of Saudi Arabia. ${ }^{4}$ Clinical Pharmacy Department, College of Pharmacy, King Saud University, Riyadh 11451, Kingdom of Saudi Arabia. ${ }^{5}$ College of Food Science \& Agriculture, Department of Food Science \& Nutrition, King Saud University, Riyadh, Kingdom of Saudi Arabia. ${ }^{6}$ Department of Health Administration, King Saud University, Riyadh, Kingdom of Saudi Arabia. ${ }^{7}$ Health Affairs for Riyadh Region, Ministry of Health, Riyadh, Kingdom of Saudi Arabia. ${ }^{8}$ Department of Clinical Lab Sciences, College of Applied Medical Sciences, King Saud University, Riyadh 11451, Kingdom of Saudi Arabia.

Received: 5 September 2013 Accepted: 10 April 2014 Published: 14 April 2014

\section{References}

1. Hildrum B, Mykletun A, Hole T, Midthjell K, Dahl AA: Age-specific prevalence of the metabolic syndrome defined by the International Diabetes Federation and the National Cholesterol Education Program: the Norwegian HUNT 2 study. BMC Public Health 2007, 7:220.

2. Wilson PW, D'Agostino RB, Parise H, Sullivan L, Meigs JB: Metabolic syndrome as a precursor of cardiovascular disease and type 2 diabetes mellitus. Circulation 2005, 112:3066-3072.

3. Alokail MS, Al-Daghri N, Abdulkareem A, Draz HM, Yakout SM, Alnaami A, Sabico S, Alenad AM, Chrousos GP: Metabolic syndrome biomarkers and early breast cancer in Saudi women: evidence for the presence of a systemic stress response and/or a pre-existing metabolic syndromerelated neoplasia risk? BMC Cancer 2013, 13:54.

4. Pischon T, Hu FB, Rexrode KM, Girman CJ, Manson JE, Rimm EB: Inflammation, the metabolic syndrome, and risk of coronary heart disease in women and men. Atherosclerosis 2008, 197:392-399.

5. Russo A, Autelitano M, Bisanti L: Metabolic syndrome and cancer risk. Eur $J$ Cancer 2008, 44:293-297.

6. Expert Panel on Detection, Evaluation, and Treatment of High Blood Cholesterol in Adults: Executive Summary of The Third Report of The National Cholesterol Education Program (NCEP) Expert Panel on Detection, Evaluation, and Treatment of High Blood Cholesterol In Adults (Adult Treatment Panel III). JAMA 2001, 285:2486-2497.

7. Cameron AJ, Shaw JE, Zimmet PZ: The metabolic syndrome: prevalence in worldwide populations. Endocrinol Metab Clin North Am 2004, 33:351-375.

8. Cornier MA, Dabelea D, Hernandez TL, Lindstrom RC, Steig AJ, Stob NR, Van Pelt RE, Wang H, Eckel RH: The metabolic syndrome. Endocr Rev 2008, 29:777-822.

9. Gupta A, Gupta R, Sarna M, Rastogi S, Gupta VP, Kothari K: Prevalence of diabetes, impaired fasting glucose and insulin resistance syndrome in an urban Indian population. Diabetes Res Clin Pract 2003, 61:69-76.

10. Ford ES, Giles WH, Dietz WH: Prevalence of the metabolic syndrome among US adults: findings from the third National Health and Nutrition Examination Survey. JAMA 2002, 287:356-359.

11. Balkau B, Vernay M, Mhamdi L, Novak M, Arondel D, Vol S, Tichet J, Eschwège $E$ : The incidence and persistence of the NCEP (national cholesterol education program) metabolic syndrome. The French D.E.S.I. R. Study. Diabetes Metab 2003, 29:526-532.
12. Ramachandran A, Snehalatha C, Satyavani K, Sivasankari S, Vijay V: Metabolic syndrome in urban Asian Indian adults-a population study using modified ATP III criteria. Diabetes Res Clin Pract 2003, 60:199-204.

13. Balkau B, Charles MA, Drivsholm T, Borch-Johnsen K, Wareham N, Yudkin JS, Morris R, Zavaroni I, van Dam R, Feskins E, Gabriel R, Diet M, Nilsson P, Hedblad B: Frequency of the WHO metabolic syndrome in European cohorts, and an alternative definition of an insulin resistance syndrome. Diabetes Metab 2002, 28:364-376.

14. Csaszar A, Kekes E, Abel T, Papp R, Kiss I, Balogh S: Prevalence of metabolic syndrome estimated by international diabetes federation criteria in a Hungarian population. Blood Press 2006, 15:101-106.

15. Ang LW, Ma S, Cutter J, Chew SK, Tan CE, Tai ES: The metabolic syndrome in Chinese, Malays and Asian Indians. Factor analysis of data from the 1998 Singapore national health survey. Diabetes Res Clin Pract 2005, 67:53-62.

16. Alberti KG, Zimmet $P$, Shaw J: Metabolic syndrome-a new world-wide definition. A consensus statement from the international diabetes federation. Diabet Med 2006, 23:469-480.

17. Bener A, Zirie M, Musallam M, Khader YS, Al-Hamaq AO: Prevalence of metabolic syndrome according to adult treatment panel III and international diabetes federation criteria: a population-based study. Metab Syndr Relat Disord 2009, 7:221-229.

18. Al Rashdan I, Al Nesef Y: Prevalence of overweight, obesity, and metabolic syndrome among adult Kuwaitis: results from communitybased national survey. Angiology 2010, 61:42-48.

19. Adams RJ, Appleton S, Wilson DH, Taylor AW, Dal Grande E, Chittleborough C, Gill T, Ruffin R: Population comparison of two clinical approaches to the metabolic syndrome: implications of the new international diabetes federation consensus definition. Diabetes Care 2005, 28:2777-2779.

20. Dallongeville J, Cottel D, Ferrieres J, Arveiler D, Bingham A, Ruidavets JB, Haas B, Ducimetière P, Amouyel P: Household income is associated with the risk of metabolic syndrome in a sex-specific manner. Diabetes Care 2005, 28:409-415.

21. Loucks EB, Rehkopf DH, Thurston RC, Kawachi I: Socioeconomic disparities in metabolic syndrome differ by gender: evidence from NHANES III. Ann Epidemiol 2007, 17:19-26.

22. Booth SL, Sallis JF, Ritenbaugh C, Hill JO, Birch LL, Frank LD: Environmental and societal factors affect food choice and physical activity: rationale, influences, and leverage points. Nutr Rev 2001, 59:S21-S39.

23. Drewnowski A, Specter SE: Poverty and obesity: the role of energy density and energy costs. Am J Clin Nutr 2004, 79:6-16.

24. Lidfeldt J, Nyberg P, Nerbrand C, Samsioe G, Schersten B, Agardh CD: Sociodemographic and psychosocial factors are associated with features of the metabolic syndrome. The women's health in the Lund area (WHILA) study. Diabetes Obes Metab 2003, 5:106-112.

25. Minehira K, Tappy L: Dietary and lifestyle interventions in the management of the metabolic syndrome: present status and future perspective. Eur J Clin Nutr 2002, 56:7

26. Al-Qahtani DA, Imtiaz ML: Prevalence of metabolic syndrome in Saudi adult soldiers. Saudi Med J 2005, 26:1360-1366.

27. Washi SA, Ageib MB: Poor diet quality and food habits are related to impaired nutritional status in 13- to 18-year-old adolescents in Jeddah. Nutr Res 2010, 30:527-534.

28. Al-Daghri NM, Al-Attas OS, Alokail MS, Alkharfy KM, Yakout SM, Sabico SB, Gibson GC, Chrousos GP, Kumar S: Parent-offsrping transmission of adipocytokine levels and their associations with metabolic traits. PLoS One 2011, 6(4):e18182.

29. Al-Nuaim AA, Al-Nakeeb $Y$, Lyons M, Al-Hazzaa HM, Nevill A, Collins $P$, Duncan MJ: The prevalence of physical activity and sedentary behaviours relative to obesity among adolescents from Al-Ahsa, Saudi Arabia: rural versus urban variations. J Nutr Metab 2012, 2012:417589.

30. Al-Daghri NM, Al-Othman A, Alkharfy KM, Alokail MS, Khan N, Alfawaz HA, Aiswaidan IA, Chrousos GP: Assessment of selected nutrients intake and adipocytokines profile among Saudi children and adults. Endocr J 2012, 59(12):1057-1063.

31. Al-Baghli NA, Al-Ghamdi AJ, Al-Turki KA, El-Zubaier AG, Al-Mostafa BA Al-Baghli FA, Al-Ameer MM: Awareness of cardiovascular disease in eastern Saudi Arabia. J Family Community Med 2010, 17:15-21.

32. Barrimah IE, Mohaimeed AR, Midhat F, Al-Shobili HA: Prevalence of metabolic syndrome among qassim university personnel in Saudi Arabia. Int J Health Sci (Qassim) 2009, 3:133-142. 
33. Al-Qahtani DA, Imtiaz ML, Saad OS, Hussein NM: A comparison of the prevalence of metabolic syndrome in Saudi adult females using two definitions. Metab Syndr Relat Disord 2006, 4:204-214.

34. Al-Daghri NM, Al-Attas OS, Alokail MS, Alkharfy KM, Yousef M, Sabico SL, Chrousos GP: Diabetes mellitus type 2 and other chronic non-communicable diseases in the central region, Saudi Arabia (Riyadh cohort 2): a decade of an epidemic. BMC Med 2011, 9:76.

35. Harte AL, da Silva NF, Miller MA, Cappuccio FP, Kelly A, O"Hare JP, Barnett AH, Al-Daghri NM, Al-Attas O, Alokail M, Sabico S, Tripathi G, Bellary S, Kumar S, McTernan PG: Telomere length attrition, a marker of biological senescence, is inversely correlated with triglycerides and cholesterol in South Asian males with type 2 diabetes mellitus. Exp Diab Res 2012, 2012:895185.

36. Fiuza M, Cortez-Dias N, Martins S, Belo A: Metabolic syndrome in Portugal: prevalence and implications for cardiovascular risk-results from the VALSIM study. Rev Port Cardiol 2008, 27:1495-1529.

37. Al-Daghri NM, Al-Attas OS, Alokail MS, Alkharfy KM, Sabico SL, Chrousos GP: Decreasing prevalence of the full metabolic syndrome but a persistently high prevalence of dyslipidemia among adult Arabs. PLoS One 2010, 5:e12159.

38. Sirdah MM, Al Laham NA, Abu Ghali AS: Prevalence of metabolic syndrome and associated socioeconomic and demographic factors among palestinian adults (20-65 years) at the Gaza Strip. Diabetes Metab Syndr 2011, 5(2):93-97.

39. Delavar MA, Lye MS, Khor GL, Hanachi P, Hassan ST: Prevalence of metabolic syndrome among middle aged women in Babol, Iran. Southeast Asian J Trop Med Public Health 2009, 40:612-628.

40. Rguibi M, Belahsen R: Overweight and obesity among urban Sahraoui women of South Morocco. Ethn Dis 2004, 14:542-547.

41. Riediger ND, Clara I: Prevalence of metabolic syndrome in the Canadian adult population. CMAJ 2011, 183:E1127-E1134.

42. Ferguson TS, Younger N, Tulloch-Reid MK, Forrester TE, Cooper RS, Van den Broeck J, Wilks RJ: Prevalence of the metabolic syndrome in Jamaican adults and its relationship to income and education levels. West Indian Med J 2010, 59:265-273.

43. Allal-Elasmi M, Haj Taieb S, Hsairi M, Zayani Y, Omar S, Sanhaji H, Jemaa R, Feki M, Elati J, Mebazaa A, Kaabachi N: The metabolic syndrome: prevalence, main characteristics and association with socio-economic status in adults living in great tunis. Diabetes Metab 2010, 36:204-208.

44. Park SJ, Kang HT, Nam CM, Park BJ, Linton JA, Lee YJ: Sex differences in the relationship between socioeconomic status and metabolic syndrome: the Korean national health and nutrition examination survey. Diabetes Res Clin Pract 2012, 96:400-406.

45. Matthews KA, Raikkonen K, Gallo L, Kuller LH: Association between socioeconomic status and metabolic syndrome in women: testing the reserve capacity model. Health Psychol 2008, 27:576-583.

46. Santos AC, Ebrahim S, Barros H: Gender, socio-economic status and metabolic syndrome in middle-aged and old adults. BMC Public Health 2008, 8:62.

47. Gulliford M: Commentary: epidemiological transition and socioeconomic inequalities in blood pressure in Jamaica. Int J Epidemiol 2003, 32:408-409.

48. Kaplan GA, Keil JE: Socioeconomic factors and cardiovascular disease: a review of the literature. Circulation 1993, 88:1973-1998.

49. Alokail M, Al-Attas O, Sabico S, Kumar S: Establishing abdominal height cut-offs and their association with conventional indices of obesity among Arab children and adolescents. Ann Saudi Med 2010, 30:209-214

50. Al-Hazzaa HM, Musaiger AO, Arab Teens Lifestyle Study Research Group: Physical activity patterns and eating habits of adolescents living in major Arab cities. the Arab teens lifestyle study. Saudi Med J 2010, 31:210-211.

51. Musaiger AO: Overweight and Obesity in the Arab Countries: the Need for Action. Bahrain: Arab Center for Nutrition; 2007.

52. Garn SM: Family-line and socioeconomic factors in fatness and obesity. Nutr Rev 1986, 44:381-386.

53. Zhang $\mathrm{Q}$, Wang $Y$ : Socioeconomic inequality of obesity in the United States: do gender, age, and ethnicity matter? Soc Sci Med 2004, 58:1171-1180

54. Yang X, Tao Q, Sun F, Zhan S: The impact of socioeconomic status on the incidence of metabolic syndrome in a Taiwanese health screening population. Int J Public Health 2012, 57:551-559.

55. Wardle J, Waller J, Jarvis MJ: Sex differences in the association of socioeconomic status with obesity. Am J Public Health 2002, 92:1299-1304.
56. Zhan Y, Yu J, Chen R, Gao J, Ding R, Fu Y, Zhang L, Hu D: Socioeconomic status and metabolic syndrome in the general population of China: a cross-sectional study. BMC Public Health 2012, 12:921.

57. Kaduka LU, Kombe Y, Kenya E, Kuria E, Bore JK, Bukania ZN, Mwangi M: Prevalence of metabolic syndrome among an urban population in Kenya. Diabetes Care 2012, 35:887-893.

58. Kim MH, Kim MK, Choi BY, Shin YJ: Educational disparities in the metabolic syndrome in a rapidly changing society-the case of South Korea. Int J Epidemiol 2005, 34:1266-1273.

59. Park MJ, Yun KE, Lee GE, Cho HJ, Park HS: A cross-sectional study of socioeconomic status and the metabolic syndrome in Korean adults. Ann Epidemiol 2007, 17:320-326

60. Hjartaker A, Lund E: Relationship between dietary habits, age, lifestyle, and socio-economic status among adult Norwegian women. The Norwegian women and cancer study. Eur J Clin Nutr 1998, 52:565-572.

61. Luepker RV, Rosamond WD, Murphy R, Sprafka JM, Folsom AR, McGovern PG, Blackburn H: Socioeconomic status and coronary heart disease risk factor trends. The Minnesota heart survey. Circulation 1993, 88:2172-2179.

62. Wardle J, Parmenter $K$, Waller J: Nutrition knowledge and food intake. Appetite 2000, 34:269-275.

63. le Son NT, Kunii D, Hung NT, Sakai T, Yamamoto S: The metabolic syndrome: prevalence and risk factors in the urban population of Ho Chi Minh City. Diabetes Res Clin Pract 2005, 67:243-250. 65.

64. Al-Eisa: Indicators of adherence to physiotherapy attendance among Saudi female patients with mechanical low back pain: a clinical audit. BMC Musculoskelet Disord 2010, 11:124.

65. Mabry RM, Reeves MM, Eakin EG, Owen N: Evidence of physical activity participation among men and women in the countries of the gulf cooperation council: a review. Obes Rev 2010, 11:457-464.

doi:10.1186/1471-2261-14-5

Cite this article as: Al-Daghri et al:: Gender-dependent associations between socioeconomic status and metabolic syndrome:

a cross-sectional study in the adult Saudi population. BMC Cardiovascular Disorders 2014 14:51.

\section{Submit your next manuscript to BioMed Central and take full advantage of:}

- Convenient online submission

- Thorough peer review

- No space constraints or color figure charges

- Immediate publication on acceptance

- Inclusion in PubMed, CAS, Scopus and Google Scholar

- Research which is freely available for redistribution 